\title{
Introduction to the Indications and Procedures
}

Cornelia Seidlitz, Miriam Kip

1.1 Definition -2

1.2 Etiology, Indications and Treatment Goals - 2

1.2.1 Etiology -2

1.2.2 Indications -6

1.2.3 Surgery Goals and Objectives -8

1.3 Materials, Surgical Procedures and Risks - 8

1.3.1 Material Requirements -8

1.3.2 Surgery -9

1.3.3 Factors Influencing Treatment Success and Complications -10 References -13 


\section{Summary}

Arthroplasty is defined as the surgical replacement of a joint with artificially produced material. Total arthroplasty refers to the replacement of all joint surfaces concerned, while partial replacement involves the replacement of only one or some of the surfaces but not the entire joint. Hip and knee joints are those that are most frequently replaced. The most common indications for hip or knee arthroplasty are symptomatic osteoarthritis and femoral neck fractures (hip). When patients undergo hip or knee replacement for the first time (due to osteoarthritis) they are usually between 60 and 70 years of age. More than two thirds of patients who undergo arthroplasty due to femoral neck fractures are over 85 years of age. Primary arthroplasty refers to the first hip or knee replacement and revision arthroplasty refers to follow-up surgery on the same joint. The period of time (without complications) between primary arthroplasty and revision arthroplasty is termed as »service life«. In symptomatic osteoarthritis, arthroplasty is performed after all conservative and joint preserving therapy options have been exhausted. With regard to femoral neck fractures, joint replacement is usually the primary treatment option. Surgery aims to improve the quality of life, to restore the greatest possible functionality, mobility and freedom from pain, to assure a long service life with good weight-bearing capacity and to avoid secondary complications. These constitute important prerequisites for leading an independent life in old age.

\subsection{Definition}

Arthroplasty is defined as the essential surgical replacement of a joint with artificially produced material which is fixated in the bone (joint replacement, endoprosthetic surgery, alloarthroplasty) (Claes et al. 2012; Wirtz 2011). Total replacement refers to the replacement of all the joint surfaces concerned while partial replacement involves the replacement of only one or some of the surfaces but not the entire joint. Hip and knee joints are the most frequently replaced, but endoprosthetic implants are also used to replace other joint functions, such as shoulder or elbow joints (Claes et al. 2012; Wirtz 2011).
The most common reason for joint replacements is joint surface destruction from wear of the cartilage lining due to degenerative diseases such as osteoarthritis, fractures and other changes in bone and connective tissue structures. Under certain circumstances, these can lead to permanent loss of function, permanent pain and impaired mobility of the affected joint, as well as a decrease in quality of life. If these symptoms cannot be treated otherwise, replacement with an artificial joint becomes necessary in order to avoid secondary complications and to restore the patient's ability to participate adequately in everyday life.

The causes and consequently also the risk of requiring joint replacements are largely dependent on age. On average, patients are aged between 60 and 70 years when they receive an artificial hip or knee joint replacement for the first time.

\subsection{Etiology, Indications and Treatment Goals}

\subsubsection{Etiology}

Symptomatic osteoarthritis constitutes the most common reason for requiring hip joint replacement (Claes et al. 2012; Wirtz 2011). Over $80 \%$ of all primary hip surgery is due to osteoarthritis-related symptomatic degenerative changes in the articular surfaces (osteoarthritis of the hip) (Barmer GEK 2010). Other reasons include periarticular fractures, such as femoral neck fractures (Strohm et al. 2015), chronic inflammatory rheumatic diseases, misalignments and pathological changes of the bone substance, due to tumors for example, metastases or osteoporosis, which increase the risk of periarticular fractures (Claes et al. 2012).

In the majority of cases, osteoarthritis also constitutes the main reason for requiring knee joint replacement (osteoarthritis of the knee). Osteoarthritis is responsible for $96 \%$ of all primary endoprosthetic procedures on the knee (Barmer GEK 2010). Other reasons for knee joint replacements are much less frequent (Wirtz 2011). 
Tab. 1.1 Osteoarthritis classification and risk factors (selection)

\begin{tabular}{|c|c|c|}
\hline Classification & Risk factors & Description \\
\hline $\begin{array}{l}\text { Primary } \\
\text { (idiopathic) }\end{array}$ & & $\begin{array}{l}\text { localized (hip, knee) or generalized (polyosteoarthritis, more than } \\
\text { three joint regions affected) }\end{array}$ \\
\hline \multirow[t]{5}{*}{ Secondary } & $\begin{array}{l}\text { congenital and acquired joint } \\
\text { defects }\end{array}$ & e.g. hip dysplasia, malalignments of the knee \\
\hline & endocrine diseases & e.g. diabetes mellitus \\
\hline & metabolic disorders & e.g. hemochromatosis, hypercholesterolemia, hyperuricemia \\
\hline & posttraumatic & $\begin{array}{l}\text { e.g. following joint fractures, fractures near the hip, cruciate liga- } \\
\text { ment injury in the knee }\end{array}$ \\
\hline & other causes & $\begin{array}{l}\text { e.g. sepsis, inflammatory rheumatic disease, circulatory disorders } \\
\text { of the bone near the joint in avascular necrosis of the femoral head } \\
\text { and femoral condyle }\end{array}$ \\
\hline
\end{tabular}

Source: IGES - Günther et al. 2013

\section{- Osteoarthritis}

Numerous potential risk factors for osteoarthritis-related joint changes exist (•Tab. 1.1). If these risk factors cannot be clearly ascertained, the osteoarthritis is classified as primary or idiopathic. In contrast, secondary osteoarthritis has one or more identifiable risk factors that may contribute to the advancement of the disease. General risk factors include age, sex as well as genetic, biomechanical and inflammatory factors. In addition body weight, osteoporosis, cardiovascular and metabolic diseases can also negatively affect cartilage metabolism. Risk factors resulting in local effects include injuries, circulatory disorders, congenital or acquired malformations and too much strain on only one side of the joint. As a result, multicausal rather than monocausal explanatory models are therefore generally favored nowadays (Günther et al. 2013).

The main symptoms of osteoarthritis are pain and increased restriction in mobility of the affected joints. In most cases, the disease usually progresses chronically, initially with symptoms such as joint stiffness which at first only occur after a longer period of strain on the affected joint. At first, pain only occurs following certain movements or after longer periods of rest (pain on initial movement). At a later stage, the pain is not associated with strain and becomes continuous (resting pain, nocturnal pain) (Claes et al. 2012).
Osteoarthritis is characterized by an imbalance in the cartilage metabolism in which catabolic processes prevail. Cartilage degeneration initially leads to the formation of new less resistant cartilage tissue. Therefore, joint function is restored but the joint is less resistant to strain. Over time, the cartilage tissue can be completely destroyed and the exposed bone underneath becomes deformed and the joint thickens (Claes et al. 2012).

In the advanced stage (active osteoarthritis) the increasing destruction of cartilage tissue and consequent inflammation of the synovial membrane lead to acute episodes of pain, movement restriction, swelling, joint warmth and sensations of tension. Sensitivity to weather, heat and cold are also typical symptoms during this phase. Generally, this stage of the disease can last several years and can include phases with and without symptoms (Claes et al. 2012) (• Fig 1.1).

During the late stage of the disease (decompensated osteoarthritis), the progressive destruction of the joint is accompanied by permanent pain and functional restrictions. This leads to diminished quality of life in patients as daily life activities (e.g. washing, getting dressed) and mobility are affected. Pain then occurs during minor movements or even at rest. Chronic pain can also develop, caused by cartilage destruction, sclerosis and the formation of bone projections (osteophytes) as well as damage to 


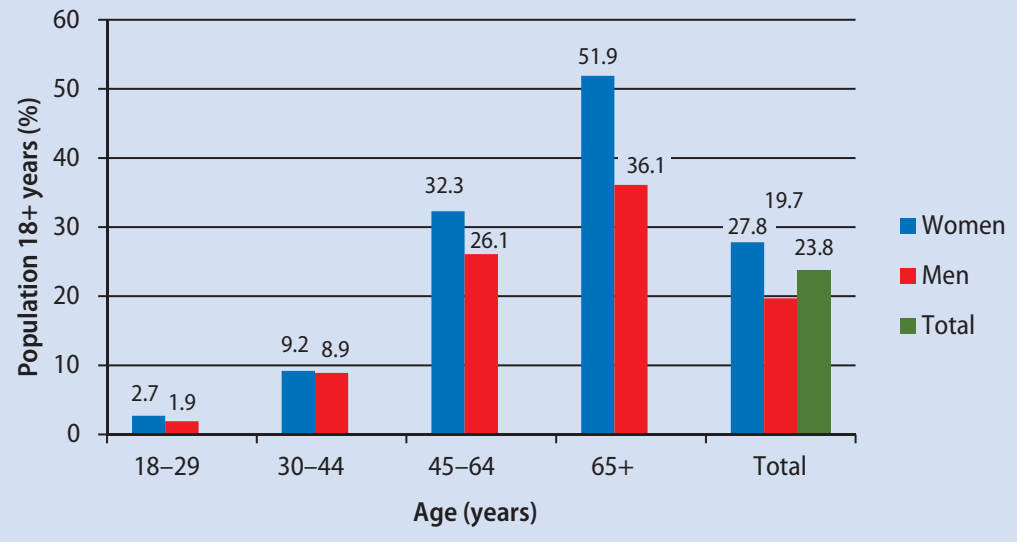

Fig. 1.1 Lifetime prevalence of osteoarthritis in Germany in 2012. (IGES - RKI 2014)

adjacent structures such as bones, muscles, capsules and ligaments. Osteoarthritis can ultimately lead to stiffness and instability of the affected joints resulting in immobility of the patient and consequently in the development of severe secondary diseases (Claes et al. 2012).

According to the Robert Koch Institute (RKI), the lifetime prevalence of osteoarthritis in Germany in 2012 was $27.8 \%$ in women and $19.7 \%$ in men. There was a noticeable rise in the prevalence of the disease in older age groups: In the 30 to 44 years age group, $9.2 \%$ of the women surveyed and $8.9 \%$ of men reported to have osteoarthritis, in the 45 to 64 years age group, $32.3 \%$ and $26.1 \%$ respectively reported to have osteoarthritis as did approximately $50 \%$ all women and $36 \%$ of men who were older than 65 years of age (- Fig. 1.1). Previous studies have shown that the prevalence of symptomatic osteoarthritis in the population is estimated to be around $10 \%$ in people over 60 years of age (Sun et al. 1997).

Due to the expected future demographic trends in Germany, a significant rise in degenerative joint diseases and therefore in hip and knee osteoarthritis requiring treatment can be expected (RKI 2009). Corresponding estimates for the increased needs of endoprosthetic care for other countries (Culliford et al. 2015; Kurtz et al. 2007) cannot be directly applied to Germany. However, prognoses published in relation to the development in musculoskeletal diseases
(Ewerbeck and Dreinhofer 2009) together with estimates from the German Society for Orthopaedics and Trauma (Deutsche Gesellschaft für Orthopädie und Unfallchirurgie e. V.) (DGOU)) (Schmitt 2014) based on demographic trends and disease burdens give reason to expect an increase in these age-related diseases the future. An increase in the number of heavily overweight people in the population constitutes another influencing factor that will play an important role with regard to knee joint replacements (Derman et al. 2014).

\section{- Femoral neck fracture}

Besides osteoarthritis, another important risk factor for hip joint replacement is the femoral neck fracture. It gains growing importance with increasing patient age (Claes et al. 2012; Strohm et al. 2015). Femoral neck fractures are close to the joint and require surgical treatment in most cases. Conservative therapy is only possible in cases of stable, non-impacted fractures. The surgical procedures available include procedures that preserve the joint and endoprosthetic procedures. The procedure selected will depend on the type of fracture and the age of the patient, amongst other factors. Usually, an endoprosthesis is implanted in patients over 65 years of age and in patients already suffering from joint osteoarthritis (Pfeifer et al. 2001). Osteosynthetic procedures aim to preserve the joint with the help of locking nails, cannulated screws or dynamic 
hip screws consisting of extramedullary plates and antirotation screws (Claes et al. 2012).

The most common causes of femoral neck fractures are falls that occur at home which in turn can be ascribed to underlying diseases, for instance neurological or heart diseases.

A femoral neck fracture is one of the most common late-stage complications of osteoporosis (Stöckle et al. 2005). The prevalence of osteoporosis amongst the over 50 age group is approximately $14 \%$ (women: $24 \%$; men: $6 \%$ ) (Hadji et al. 2013).

Factors which contribute to femoral neck fractures include age-related reduced bone mineral density and a higher risk of falling. Risk factors for falls include vitamin D deficiency (which affects the muscles), coordination disorders (for example due to medication), dizziness, defective vision, weakness, multimorbidity or existing diseases of the musculoskeletal system. The average age of patients with femoral neck fractures is relatively high and hence rapid mobilization is particularly important in order to avoid further complications. Preservation of the femoral head is given primary importance solely in younger patients (Claes et al. 2012).

Femoral neck fractures in younger patients are rare and are usually the result of so-called high-energy traumas, i.e. road traffic accidents and falls from great heights. Additionally, malignant diseases that are accompanied by bone destruction can also lead to femoral neck fractures (pathological fractures).

Femoral neck fractures are associated with severe pain in the hip region, restricted mobility of the hip joint and on walking. Often, the affected leg is noticeably shorter and rotated outwards. External signs of injury include hematomas or swelling above the hip joint. In cases of impacted fractures, clinical signs can be very discrete in that patients may still be able to walk for several days despite the fracture (Claes et al. 2012).

The risk of femoral neck fractures in one's lifetime is indicated to be between $11 \%$ to $23 \%$ in women and $5 \%$ to $11 \%$ in men (Stöckle et al. 2005).

This incidence rises with increasing age with a marked increase from the age of 74 years in particular (RKI 2009). Consequently, with a steadily increasing proportion of older people in the population, it can be assumed that the absolute number of femoral neck fractures will also rise (Berufsverband der Fachärzte für Orthopädie e. V. 2004, Pfeifer et al. 2001). Given the current demographic trends in $\mathrm{Eu}-$ rope, it is assumed that the incidence of femoral fractures will increase by at least fourfold over the next 60 years.

To date, only limited data from studies on the incidence of femoral neck fractures in Germany is available. An epidemiological investigation based on hospital statistics from 2004 found an incidence of 140.9 per 100,000 inhabitants. In correlation with the age-dependency, the incidence in older population groups (over 65 years) was significantly higher (662 per 100,000 inhabitants as opposed to 21.7 per 100,000 inhabitants in groups aged below 65 years) and was also significantly higher in women than in men (Icks et al. 2008).

According to the latest hospital diagnoses data, the number of inpatient cases in 2013 was 144 per 100,000 inhabitants (age standardized). The number of cases in the over 65 years of age group was at 875 cases per 100,000 inhabitants and as expected, women were affected more than twice as often as men (• Fig. 1.2).

\section{- Femoral head necrosis}

In femoral head necrosis the bone tissue of the femoral head dies (osteonecrosis). This is a result of ischemia (circulatory disorder) of the affected area (Meizer et al. 2007).

Inadequate blood supply can result from traumatic factors (posttraumatic osteonecrosis), such as tearing or overstretching following a femoral neck fracture, or various different risk factors and underlying diseases (nontraumatic osteonecrosis). There are several different risk factors and underlying diseases which can lead to nontraumatic osteonecrosis. Identifiable risk factors which are observed in $50 \%$ to $80 \%$ of cases include alcohol and nicotine abuse, dyslipidemia, pregnancy and hereditary coagulation disorders such as thrombophilia. In addition, high-dose corticosteroid intake (for example, for chronic inflammatory diseases) is associated with a high risk of disease development. Diseases that have been observed to result in higher rates of femoral head necrosis include systemic lupus erythematosus, HIV, malignancies, and inflammatory bowel diseases, amongst others. 


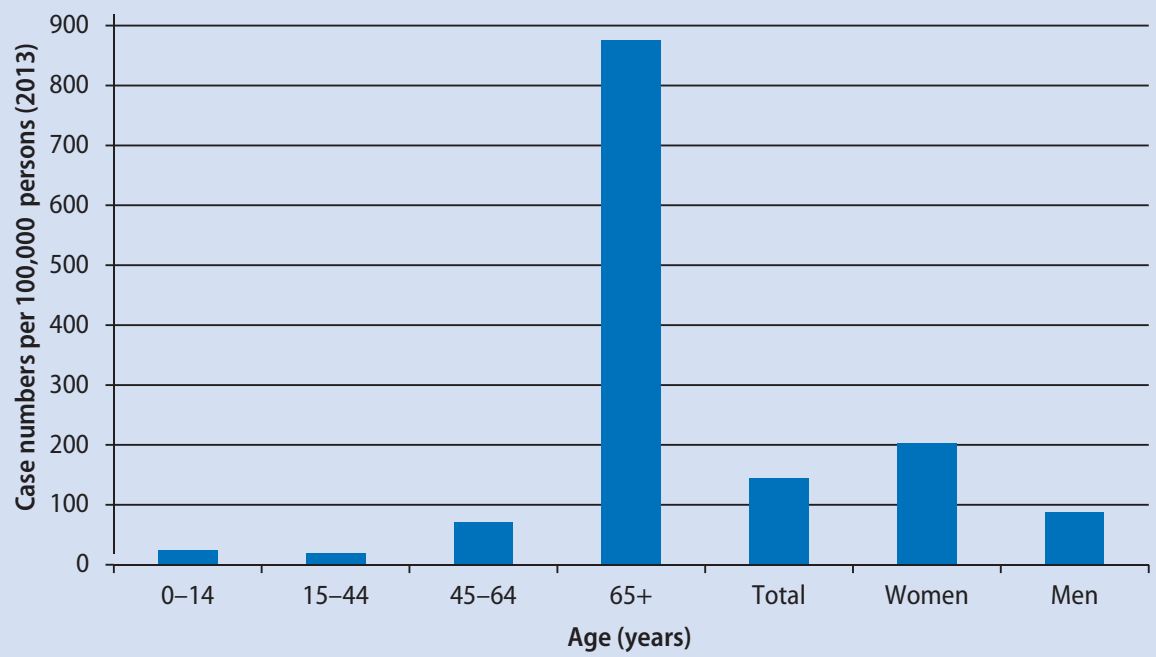

Fig. 1.2 Inpatient case numbers per 100,000 inhabitants with a femoral fracture (S72) by age group and by sex (agestandardized) (2013). (IGES - Federal Statistical Office 2014)

Symptoms associated with femoral head necrosis vary greatly between individuals and are nonspecific (Hofmann et al. 2002). Particularly at the start of the disease, which advances bilaterally in $30 \%$ to $70 \%$ of cases, there may initially be no symptoms such as pain on weight bearing or difficulty walking. During the later stage, femoral head necrosis leads to movement restrictions and strong recurrent hip pain radiating into the thigh and knee. With the progression of the disease, pain at rest may also occur and in the final stages of the disease osteoarthritis of the hip with complete destruction of the joint may occur (AWMF 2009b).

Early diagnosis of femoral head necrosis is crucial to joint-preserving treatment and improved long-term prognosis. In $85 \%$ of patients, the disease will progress within two years if the initial diagnosis is left untreated and results in femoral head collapse with complete destruction of the joint in over half of the patients (Hofmann et al. 2002). Based on the criteria developed by the Association Research Circulation Osseous (ARCO), idiopathic femoral head necrosis (without any known cause) is categorized into five different stages ( 0 to IV). The progression of each stage varies greatly between individuals and the duration can also vary from a period of several days to several years (ARCO classification) (AWMF 2014).

In German-speaking countries, the incidence of femoral head necrosis is estimated at $0.01 \%$, which corresponds to approximately 5,000 to 7,000 patients a year (Hofmann et al. 2002). The disease occurs mainly between the ages of 25 and 55 years with a peak at 35 years of age. Men are affected four times as often as women. According to a routine data analysis conducted by the Barmer GEK, bone necrosis was indicated as the relevant main diagnosis upon discharge in approximately $3 \%$ of primary total hip arthroplasty (THA) cases (Barmer GEK 2010).

\subsubsection{Indications}

\section{- Primary arthroplasty}

The indication for a hip or knee replacement is based on patient-relevant clinical and radiological criteria together with a thorough examination of the patient's medical history (Claes et al. 2012, Wirtz 2011).

The clinical diagnosis includes an examination of the affected joint as well as of the structures and 
tissue surrounding the joint. It also includes functional tests and pain assessments, for example, determining how far the patient can walk free of pain. The mobility of the joint can only be assessed by clinical examination. In addition, pain and other complaints can be evaluated by means of standardized patient surveys (AWMF 2009a, 2008; Claes et al. 2012; Wirtz 2011).

Besides objective criteria, a patient's degree of suffering and his or her requirements at the time of the examination play a substantial role in the decision for or against replacement of the affected joint. For instance, a replacement should not be recommended if the radiological findings show a joint affected by osteoarthritis but the patient does not have osteoarthritis-related symptoms or does not have many complaints (AWMF 2009a, 2008; Claes et al. 2012; Wirtz 2011).

According to Claes et al. (2012), an indication for a hip joint replacement exists if a patient's quality of life is severely affected by pain or functional impairment. Additional factors include conservative therapies that are insufficiently effective (medication, avoiding strain on the affected joint, physiotherapy, physical therapy, etc.) as well as visible causative radiological changes such as morphological joint damage, which cannot be treated conservatively (Claes et al. 2012). Furthermore, indications for hip joint replacements exist for patients over the age of 60 years who have femoral neck fractures and in patients with femoral fractures due to pathological bone diseases (for example metastases, osteoporosis) (Claes et al. 2012).

According to Wirtz (2011), an indication for total knee arthroplasty (TKA) in primary and secondary osteoarthritis of the knee exists if the conditions are associated with severe pain and movement impairments which can be confirmed radiologically (Wirtz 2011). Both the European League Against Rheumatism (EULAR) and the US National Institutes of Health (NIH) consider the indication for a knee joint replacement to exist if, alongside the radiological evidence of osteoarthritis, a patient has continuous pain that is not manageable with drugs, or if the disease is accompanied by substantial functional impairments (EULAR 2002, NIH 2004).

\section{- Revision arthroplasty}

Revision arthroplasty entails the removal and replacement of one or more components of the hip or knee endoprosthesis. It is therefore a follow-up surgical procedure for primary hip or knee arthroplasty that is performed on the same joint.

Follow-up surgery without replacement or removal of the (entire) artificial joint can also be performed if the endoprosthesis is not functioning entirely correctly (EPRD 2015), for example to remove a hematoma (revision without replacement). The time between primary replacement and $t$ revision is termed as »service life ( EPRD 2015).

Usually, revision arthroplasty is performed after the "natural« service life of the endoprosthesis has come to an end. In some cases, however, earlier revision replacement might become necessary. Reasons for revision arthroplasty include loosening of the implant, instability of the artificial joint, extensive bacterial infections and progressive degeneration of parts of the joint that have not yet been replaced. Revision can also become necessary if functional impairments of the artificial joint severely restrict a patient's activities and are often accompanied by pronounced pain. Additionally, acute or chronic infections as well as traumatic fractures close to the joint or the endoprosthesis as well as problems with the implant and the primary replacement procedure may make revision replacement necessary. Other reasons include local inflammatory tissue reactions, wear (micro-abrasive particles) of the endoprosthetic material and the quality of the endoprosthesis fixation. Patient compliance and characteristics such as age or weight also have a significant impact on the endoprosthetic service life (Section 1.3.3). Documented arthroplasty in the German joint replacement registry »Endoprothesenregister Deutschland (EPRD) « will enable a reliable determination of the service life in future, which can be related to the different levels of care such as to the surgeon, the hospital performing endoprosthetic surgery, the individual endoprosthesis and the type of endoprosthesis depending on the initial documentation. 


\subsubsection{Surgery Goals and Objectives}

Primary arthroplasty aims to restore joint function as much as possible, to reduce pain caused by osteoarthritis (hip or knee) and by other diseases. It also aims to rapidly mobilize patients after femoral neck fractures. A further goal is to achieve a long service life with good weight-bearing capacity and to avoid (secondary) complications. On the whole, a patient's quality of life should be improved and their mobility enhanced (Claes et al. 2012; Wirtz 2011). Mobility is a basic prerequisite for leading an independent life and preserving patients from social isolation, especially in older age groups (Moon 2014).

\subsection{Materials, Surgical Procedures and Risks}

\subsubsection{Material Requirements}

Ideally, the primary endoprosthesis should be retained over a lifetime. Despite tremendous technical advances and the availability of high-quality materials, this cannot be achieved for all patients. In general, both hip and knee endoprostheses are weight bearing body parts and must be designed accordingly, also with regard to the material selected (Claes et al. 2012, Wirtz 2011).

The implants undergo extensive testing with regard to functionality, quality, reliability and safety which constitutes a prerequisite for statutory product requirements. Corresponding requirements can be found in international standards which are reviewed every five years (BVMed 2014).

Regardless of the field of application, implants must have the longest possible durability which why is hard-wearing materials with minimal wear even when used in combination with other materials are employed. In addition, the materials must be accepted by the body as there is risk of potential rejection. It is recommended that metals (such as cobaltchromium and titanium alloys) be used which are connected to the bone and tribologically paired with synthetic materials (polyethylene) or ceramics (NICE 2014).
Meanwhile, many different variations of these artificial joints exist. Therefore, a short overview of how they function and the most important features is provided in the following paragraphs.

Nowadays, hip endoprostheses usually consist of an acetabular cup and a femoral stem onto which a modular endoprosthesis head is attached. The cup may consist of one piece (usually polyethylene) or of a metal cup with an inlay (modular cup). Frequently, fractures in elderly people are treated by solely replacing the femoral head with a so-called hemiendoprosthesis without replacing the cup. In this case, a (usually modular) head which has the size of the natural femoral head is attached to the endoprosthetic stem. Special procedures such as surface replacements are of minor relevance for hip joints (Claes et al. 2012).

Parts of the knee joint or the joint surface are replaced by bowl-shaped implants on the femoral side and a tibial baseplate, which can be fixated into the medullary cavity with or without a stem. The bearing surface between the femur and the tibia can be connected with the baseplate or be mobile and gliding. The back of the patella may be replaced with an implant (Wirtz 2011).

The contact surface between the bone and implant is of great importance for weight bearing on the joint after surgery. This connection technique is generally referred to as fixation. An implant can be fixated with or without bone cement - combined solutions are termed hybrid fixation or partial cementation. The applied bone cement is a special artificial cement (polymethylmethacrylate). Uncemented endoprosthesis components can have a special surface design or coating (e.g. titanium specifications or hydroxylapatite) in order to support secondary bone ingrowth. Primary stable fixation is achieved by fixing the endoprosthesis to the bone (so-called press-fit) (Claes et al. 2012; Wirtz 2011) with the aim of permanently attaching the endoprosthesis to the bone bed. Opinions on the advantages and disadvantages of cemented an uncemented fixation vary and the choice of procedure depends on different factors (such as age and bone quality) (see Section 1.3.3) (Claes et al. 2012, Wirtz 2011). 


\subsubsection{Surgery}

Prior to surgery the physician informs the patient of any possible complications and risks. Specific treatment planning includes selecting the appropriate endoprosthesis based on clinical and radiological criteria as well as deciding on the surgical access route (• Fig. 1.3).

In hip arthroplasty, the natural structures of the pelvis and the upper leg are usually replaced, i.e. the acetabulum in the pelvis and part of the femoral shaft as well as the femoral head in the upper leg. When all these structures are replaced, the procedure is referred to as total replacement or total arthroplasty. Total arthroplasty also includes short stem femoral head prostheses, which are usually used in younger patients, as well as surface replacement prostheses.

If the acetabular cup does not need replacing, the procedure is termed as partial replacement, hemiarthroplasty or partial arthroplasty. An example of this is the dual head prosthesis, which is particularly used in cases of femoral neck fractures in elderly patients (Claes et al. 2012).

The accuracy of the endoprosthetic fit is tested regularly by means of a trial prosthesis while the joint is being surgically prepared. The surgeon must ensure that there is enough tension on the ligaments and the soft tissue for the artificial joint to glide and to avoid dislocation. The implantation of the actual endoprosthesis is performed either with or without bone cement. Subsequently, the surgical access route is closed. The position of the endoprosthesis is checked by $\mathrm{x}$-ray immediately after surgery (Claes et al. 2012).

Special care must be taken when positioning the patient during arthroplasty. Cushioning materials are used to prevent pressure points on the patient and warming systems are used to prevent hypother-

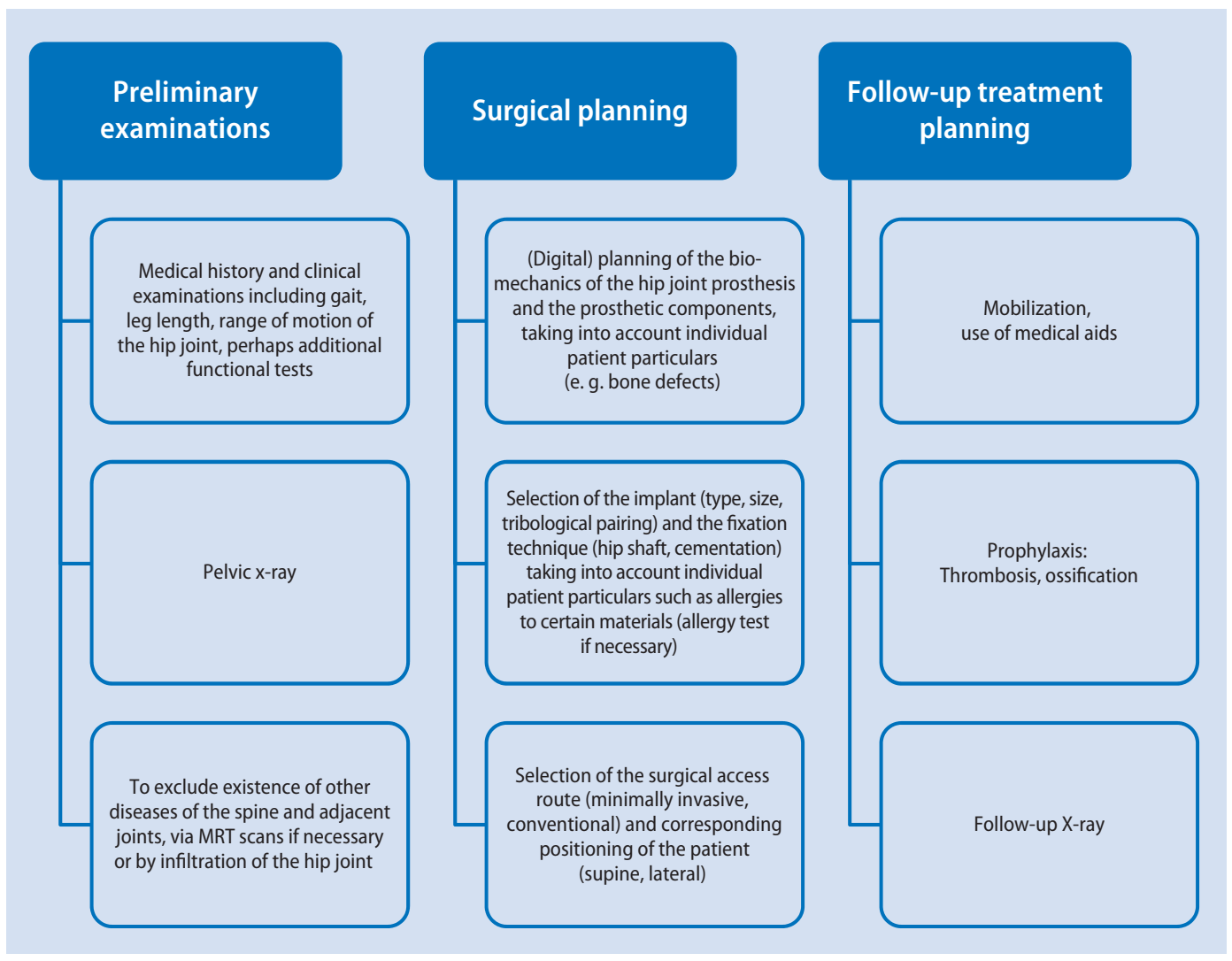

- Fig. 1.3 Elements of treatment planning based on hip arthroplasty. (IGES - Wilken et al. 2014) 
mia. The patient can be placed in a lateral or supine position. It is important to accurately secure the patient in the selected position with the help of props and straps in order to avoid any changes in position during the surgery (Claes et al. 2012).

In knee arthroplasty, parts of the upper leg (distal femur) and the lower leg (proximal tibia) are replaced with artificial material. Different types of implants are used depending on the nature and severity of the underlying disease. Structures that are usually replaced include portions of the femoral bone (femoral component) to substitute the defective condyle as well as parts of the lower leg around the tibial plateau (tibial component) and the menisci. The patella may or may not be replaced. A synthetic component is placed on the tibial component in order to minimize friction between the tibial and femoral components (»inlay«) (Wirtz 2011).

Unicondylar surface replacement, i.e. on one side of the joint only, is possible if knee function is not yet severely impaired by cartilage abrasion and the bone is affected on only one side of the knee joint. Usually, the medial (inner) side is replaced. Besides the structure of the cartilage and bone, the condition of the ligaments is also crucial to decision making. Unilateral surface replacement is often termed unicompartmental knee replacement using a unicondylar sled prosthesis that may also be referred to as sled prosthesis or mono-sled (Wirtz 2012)

Bicondylar and hinge prostheses are used for total knee arthroplasty. Here, the degree of coupling is an important distinguishing factor. Hinge prostheses are axially supported. Usually, this type of prosthesis is selected if the ligamentous apparatus is severely impaired because the hinge significantly restricts mobility. However, surface replacement prostheses without coupling or with partial coupling are used more frequently. A prerequisite for using these types of endoprosthesis is sufficient functionality of the patient's ligamentous apparatus. The artificial knee is often fixated with bone cement, but uncemented or hybrid fixation is also feasible (Wirtz 2011).

Positioning during knee arthroplasty is designed to allow frequent changes in position of the leg as specific steps during treatment require the extremities to be mobile. Therefore, rolls and special leg holders are used allowing the leg to be positioned in an upright 90 degree position (Wirtz 2011).

Numerous studies on various surgical access routes for both the hip and the knee joint exist. However, no significant advantage in any one of the particular procedures has been shown. Less invasive access routes have been advocated in recent years, as they reduce the extent of tissue incision. However, actual clinical effectiveness is a matter of debate and they may also bear a higher risk of complications. In hip revision surgery, for instance, the initial access route used during primary surgery is often used again. Additionally, these procedures require more extensive imaging of tissue and bone structures (Claes et al. 2012; Wirtz 2011).

\section{- Anesthesia}

Two anesthetic techniques can be used for both endoprosthetic hip and knee surgery: general anesthesia and regional anesthesia. General anesthesia requires artificial ventilation and is based on anxiolysis, analgesia, muscle relaxation and sedation. Under certain circumstances, regional anesthesia, in which the patient is conscious, may also be used in the form of spinal anesthesia or by blocking peripheral nerves or regions with a single injection or by continuous application by means of a catheter. General and regional anesthesia can be used alone or in combination. Anesthesia aims to allow for pain-free surgery, rapid mobilization after surgery and as much pain reduction as possible in the early rehabilitation phase (Claes et al. 2012, Wirtz 2011).

\subsubsection{Factors Influencing Treatment Success and Complications}

A number of factors can influence the success of joint replacement treatment (• Fig. 1.4). Besides the design of the implant and surgical procedure, a patient's individual characteristics can impact total hip and knee arthroplasty outcomes. These characteristics include age, sex, degree of preoperative osteoarthritis and functional status of the joint in question. Additionally, concomitant diseases (particularly obesity, cardiovascular diseases, diabetes mellitus and immune system disorders) can lead to perioperative and postoperative complications. 


\section{Patient}

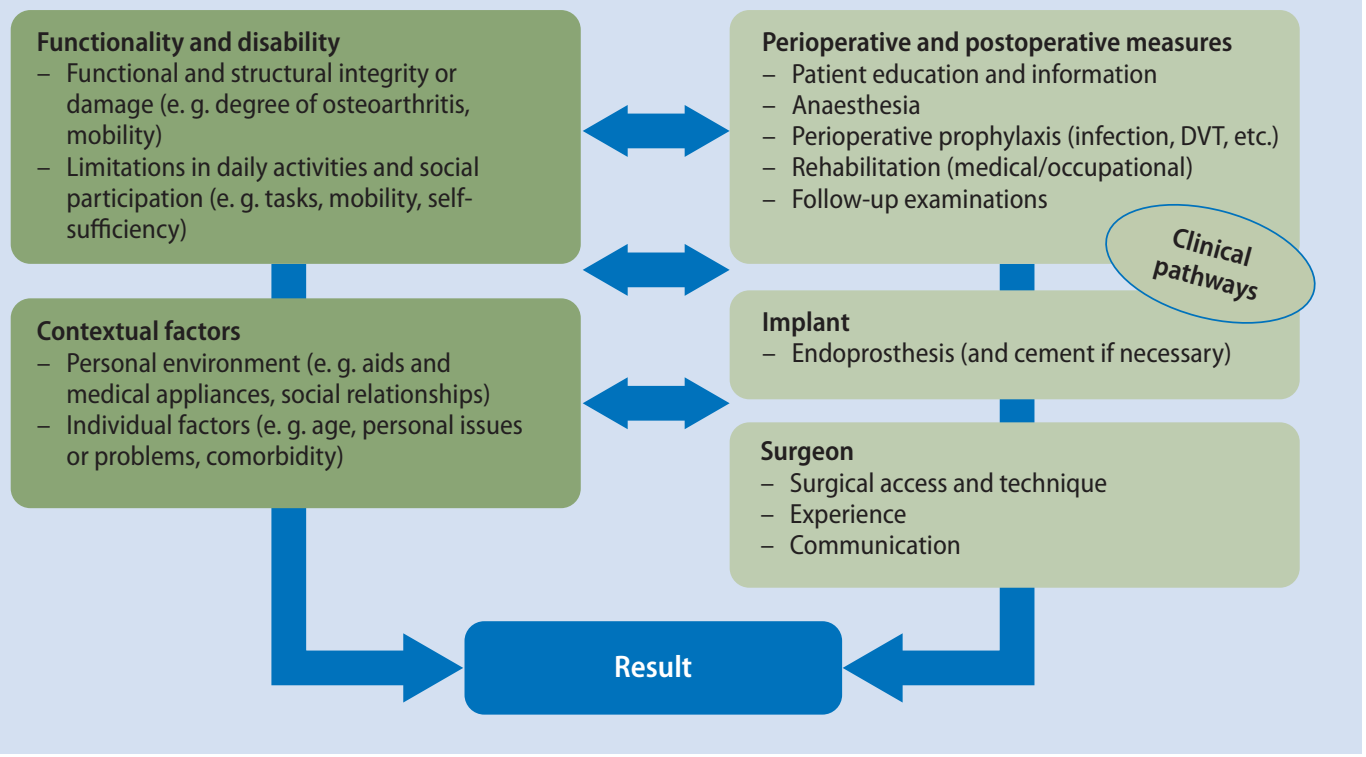

- Fig. 1.4 Factors influencing treatment success. (IGES - Günther et al. 2015)

Social deprivation, personality traits and patient expectations with regard to the surgery also play an influencing role (Günther et al. 2015; Schäfer et al. 2010). Patient compliance, i.e. the degree to which a patient correctly follows medical advice with regard to daily care of the joint, constitutes a further important factor in the success of joint replacement.

Optimal presurgical planning is important, including investigation into risk factors of a patient that are potentially modifiable. Well-planned postoperative rehabilitation treatment (ambulatory or inpatient rehabilitation) contributes to treatment success (Claes et al. 2012; Wirtz 2011) and plays an important role in attaining longer service life of an implant, high patient satisfaction and cost-effectiveness (Krummenauer et al. 2008; Krummenauer et al. 2006).

Arthroplasty procedures are associated with potential risks caused by surgical and anesthetic procedures in general or with the insertion of the implant itself. Joint replacement can involve the following major risks (Anonymous, Günther et al. 2015):

- Inflammation and suppuration (periprosthetic infection): Artificial joint replacements are always associated with an increased risk of in- flammation (infection) because pathogens (bacteria) that enter the body or that already exist therein tend to accumulate on the surface of foreign bodies. Once a certain number of bacteria have accumulated, pus may begin to develop around the implant. These infections can occur shortly after the operation (»early infection«) or later (»late infection«). The risk of infection can vary between different patient groups. Patients with diseases associated with a weakened immune system in particular bear a higher risk of infection. These diseases include diabetes mellitus and rheumatic diseases. Moreover, patients who have a focus of infection in other parts of the body or who suffer from obesity have a higher risk of infection. The risk of infection is reduced through the administration of antibiotics during surgery.

- Blood clots (thrombosis and embolism): The formation of blood clots constitutes a general risk in surgery of the knee and hip joints. Antithrombotic drugs are recommended for the prevention of thrombosis.

- Nerve damage: During surgery, inadvertent damage to the nerves may occur through phy- 
sical manipulation such pressure or tension in the regions concerned. Regional anesthesia may also cause nerve damage. Congenital hip dislocation also constitutes a risk factor as the leg may become over extended during hip joint surgery.

- Injury of blood vessels and postoperative bleeding: Surgery on the hip or knee joint is generally associated with the risk of injury to blood vessels close to the joint. Moreover, despite adequate hemostasis, postoperative bleeding may occur due to antithrombotic therapy.

- Leg length inequality and dislocations constitute specific risks during hip joint replacement: When hip joints are replaced, the aim is to achieve equal leg lengths. However, the operation may lead to a lengthening and sometimes even a shortening of the affected leg. In addition, there is a risk of dislocation subsequent to surgery as on the one hand, the implant is not an identical copy of the joint and on the other hand, the surgical procedure involves opening and partially removing the stabilizing joint capsule.

- Fractures: Necessary pressure exerted during the course of this type of surgery may cause fractures in rare occasions. The risk of fractures is higher for in uncemented fixation as this requires higher pressure during insertion.

- Calcification in the tissue near the prosthesis: During the first few months following surgery, calcification may occur within the surgical wounds which can lead to reduced mobility and pain. Administration of anti-inflammatory drugs for two weeks after surgery is recommended in order to prevent this. Alternatively, irradiation of the affected region is possible.

- Loosening of the prosthesis and material wear: It is rare for the prosthesis not to have successful bone ingrowth. If the case should arise, early replacement of the prosthesis becomes necessary due to loose fit. Particulate wear debris may be released during the course of prosthesis use, which can contribute to loosening of the implant. However, given the quality of materials currently in use there is only a slight risk of such an abrasion occurring and hence individual prosthesis components rarely break for this reason. However, if they do break, it is usually due to loosening of the prosthesis.

- Allergies: Even though it is still currently unclear if allergies to parts of the prosthesis increase the risk of complications, specific materials in the prosthesis should be avoided should a patient be allergic to them. About $10 \%$ of the population is allergic to nickel, for example.

- Persisting complaints: Besides the complications described, bursitis or tendonitis, for example, may cause persisting complaints following surgery. This, however, has been observed in comparatively few patients.

Repeat surgery or revision replacement may become necessary due to complications. Replacing an implant is considerably more complicated than the primary replacement (primary arthroplasty) as the surgeon has to deal with less bone substance therefore increasing the likelihood of fractures and other complications. A patient may also have to undergo revision surgery in which the prosthesis is not replaced or in which only a component is added to the existing endoprosthesis (renewed operation with addition). These revisions are usually performed on the hip and knee to replace the bearing surfaces and to manage recurring hip dislocations. However, dislocations may also necessitate the replacement of an implant should this occur repeatedly (Claes et al. 2012; Wirtz 2011). 
Open Access This chapter is published under the Creative Commons Attribution NonCommercial 4.0 International license (http://creativecommons.org/licenses/by-nc/4.0/deed.de) which grants you the right to use, copy, edit, share and reproduce this chapter in any medium and format, provided that you duly mention the original author(s) and the source, include a link to the Creative Commons license and indicate whether you have made any changes.

The Creative Commons license referred to also applies to any illustrations and other third party material unless the legend or the reference to the source states otherwise. If any such third party material is not licensed under the above-mentioned Creative Commons license, any copying, editing or public reproduction is only permitted with the prior approval of the copyright holder or on the basis of the relevant legal regulations.

\section{References}

Anonymous (2014): Vereinbarung gemäß § 10 Abs. 9 KH EntgG für den Vereinbarungszeitraum 2015 zwischen dem GKV- Spitzenverband, Berlin, dem Verband der Privaten Krankenversicherung, Köln, - gemeinsam - und der Deutschen Krankenhausgesellschaft, Berlin. https:// www.gkv-spitzenverband.de/media/dokumente/krankenversicherung_1/krankenhaeuser/budgetverhandlungen/bundesbasisfall-wert/KH_BBFW_2016.pdf [accessed: 10 November 2015].

AWMF (2008): Endoprothese bei Koxarthrose. AWMF-Leitlinien-Register [AWMF guideline register] No. 012/006. Validity expired. Guideline currently under review. Arbeitsgruppe Leitlinien der Dt. Gesellschaft für Unfallchirurgie (DGU) [guideline working group of the DGU].

AWMF (2009a): Endoprothese bei Gonarthrose. AWMF-Leitlinien-Register [AWMF guideline register] No. 012/008. Validity expired. Guideline currently under review. Arbeitsgruppe Leitlinien der Dt. Gesellschaft für Unfallchirurgie (DGU) [guideline working group of the DGU].

AWMF (2009b): Koxarthrose. AWMF-Leitlinien-Register [AWMF guideline register] No. 033/001. Deutsche Gesellschaft für Orthopädie und Orthopädische Chirurgie e. V. [German orthopedics and orthopedic surgery association].

AWMF (2014): S3-Leitlinie: Atraumatische Femurkopfnekrose des Erwachsenen. AWMF-Register Nr. 033/050. Version 1.2. Information correct as of: Februar 2014. Marburg: Arbeitsgemeinschaft der Wissenschaftlichen Medizinischen Fachgesellschaften e. V. [Association of the Scientific Medical Societies in Germany].

BARMER GEK Report Krankenhaus 2010. Schwerpunktthema: Trends in der Endoprothetik des Hüft- und Kniegelenks. Schriftenreihe zur Gesundheitsanalyse, Band 3. St. Augustin: Asgard-Verlag. ISBN: 978-537-44103-4.

Berufsverband der Fachärzte für Orthopädie e.V. [Association of the specialists in orthopedics] (2004): Weißbuch Osteoporose. Empfehlungen zur Diagnostik und Therapie der Osteoporose zur Vermeidung osteoporotischer Folgefrakturen. Berlin. http://www.boneandjointdecade. de/downloads/weissbuch_osteoporose.pdf [accessed: 30 November 2015].
BVMed (2014): Hohe Anforderungen an Medizinprodukte. (C1999 - 2016 BVMed e.V., Berlin - Portal für Medizintechnik. https://www.bvmed.de/de/recht/sicherheit/ technische-tests/_2-beispiel-hueftimplantate [accessed: 20 April 2016].

Claes L, Kirschner S, Perka C \& Rudert M (2012): AE-Manual der Endoprothetik - Hüfte und Hüftrevision. Heidelberg: Springer. ISBN: 978-3-642-14645-9.

Culliford D, Maskell J, Judge A, Cooper C, Prieto-Alhambra D \& Arden NK (2015): Future projections of total hip and knee arthroplasty in the UK: results from the UK Clinical Practice Research Datalink. Osteoarthritis and Cartilage 23(4), 594-600. DOI: 10.1016/j.joca.2014.12.022.

Derman PB, Fabricant PD \& David G (2014): The Role of Overweight and Obesity in Relation to the More Rapid Growth of Total Knee Arthroplasty Volume Compared with Total Hip Arthroplasty Volume. The Journal of bone \& joint surgery (Br) 96(11), 922-928.

EPRD (2015): Statusbericht 2014: Mit Sicherheit mehr Qualität. Berlin: EPRD Deutsche Endoprothesenregister gGmbH [Endoprostheses Register Germany] ISBN: 978-3-98176730-8.

EULAR (2002): [Recommendations of EULAR on treatment of gonosteoarthritis. Report of a committee of the "Standing Committee for International Clinical Studies Including Therapeutic Trials (ESCIST) «]. Zeitschrift für Rheumatologie 61(3), 229-243. ISSN: 0340-1855.

Ewerbeck V \& Dreinhofer K (2009): Entwicklung der Orthopädie in den nächsten 20 Jahren. Der Chirurg 80(12), 1111-1114. DOI: 10.1007/s00104-009-1773-1.

Günther KP, Fickert S \& Goronzy J (2013): Arthrose. In: Wirth CJ, Mutschler E, Kohn D \& ohlermann T: Praxis der Orthopädie und Unfallchirurgie. Stuttgart: Thieme. ISBN: 9783131406439.

Günther KP, Haase E, Lange T, Kopkow C, Schmitt J, Jeszenszky C, Balck F, Lützner J, Hartmann A \& Lippmann M (2015): Persönlichkeitsprofil und Komorbidität: Gibt es den »schwierigen Patienten« in der primären Hüftendoprothetik? Der Orthopäde 44(7), 555-565. DOI: 10.1007/ s00132-015-3097-9.

Hadji P, Klein S, Gothe H, Haussler B, Kless T, Schmidt T, Steinle T, Verheyen F \& Linder R (2013): Epidemiologie der Osteoporose: Bone Evaluation Study. Eine Analyse von Kran- 
kenkassen-Routinedaten. Deutsches Ärzteblatt 110(4), 52-57. DOI: 10.3238/arztebl.2013.0052.

Hofmann S, Kramer J \& H. Pj (2002): Die Osteonekrose des Hüftgelenks im Erwachsenenalter. Der Radiologe 42(6), 440-450. DOI: 10.1007/s00117-002-0756-8.

Icks A, Haastert B, Wildner M, Becker C \& Meyer G (2008): [Hip fracture incidence in Germany: analysis of the national hospital discharge registry 2004]. Deutsche medizinische Wochenschrift 133(4), 125-128. DOI: 10.1055/s-2008-1017485.

Krummenauer F, Günther K-P \& Witzleb W-C (2008): The incremental cost effectiveness of in-patient versus out-patient rehabilitation after total hip arthroplasty - results of a pilot investigation. European Journal of Medical Research 13(6), 267-274.

Krummenauer F, Wojciechowski C, Ranisch H, Witzleb W-C \& Günther K-P (2006): Evaluation der indirekten Kosten durch postoperative Arbeitsunfähigkeit nach Hüft-Endoprothetik aus Perspektive der Kostenträger. Zeitschrift für Orthopädie und ihre Grenzgebiete 144(5), 435-437. DOI: $10.1055 /$ s2006949582.

Kurtz S, Ong K, Lau E, Mowat F \& Halpern M (2007): Projections of Primary and Revision Hip and Knee Arthroplasty in the United States from 2005 to 2030. The Journal of Bone and Joint Surgery 89(4), 780-785.

Meizer R, Meizer E, Landsiedl F \& Aigner N (2007): Die Osteonekrose des Hüftgelenks. Journal für Mineralstoffwechsel 14(1), 12-17.

Moon S (2014): Untersuchung des Gleichgewichts und des Gangbildes bei Patienten mit Knie- und Hüftendoprothese. [Dissertation] Saarbrücken: Universität des Saarlandes, Philosophische Fakultäten III. http://d-nb. info/1058857509/34 [accessed: 30 November 2015].

NICE (2014): Total hip replacement and resurfacing arthroplasty for endstage arthritis of the hip (review of technology appraisal guidance 2 and 44) - NICE technology appraisal guidance 304. 2015/10/22/. https://www.nice. org.uk/guidance/ta304 [accessed: 22 October 2015].

NIH (2004): NIH Consensus Statement on total knee replacement December 8-10, 2003. J Bone Joint Surg Am 86-A(6), 1328-1335. ISSN: 0021-9355.

Pfeifer M, Wittenberg R, Würtz R \& Minne HW (2001): Schenkelhalsfrakturen in Deutschland. Prävention, Therapie, Inzidenz und sozioökonomische Bedeutung. Deutsches Ärzteblatt 98(26), A1751-1757.

Prokopetz JJ, Losina E, Bliss RL, Wright J, Baron JA \& Katz JN (2012): Risk factors for revision of primary total hip arthroplasty: a systematic review. BMC Musculoskeletal Disorders 13(251), 1-13. DOI: 10.1186/1471-2474-13-251.

RKI (2009): Gesundheit und Krankheit im Alter. Beiträge zur Gesundheitsberichterstattung des Bundes. Berlin: Robert Koch Institute (ed.). ISBN: 978-3-89606-196-6. https:// www.rki.de/DE/Content/Gesundheitsmonitoring/Gesundheitsberichterstattung/GBEDownloadsB/alter_gesundheit.pdf?_blob=publicationFile [accessed: 04 November 2015].
Robert Koch Institute (ed.) (2014) Arthrose. Faktenblatt zu GEDA 2012: Ergebnisse der Studie »Gesundheit in Deutschland aktuell 2012«. RKI, Berlin www.rki.de/geda (as at: 25 October 2014).

Schäfer T, Krummenauer F, Mettelsiefen J, Kirschner S \& Günther KP (2010): Social, educational, and occupational predictors of total hip replacement outcome. Osteoarthritis and Cartilage 18(8), 1036-1042. DOI: 10.1016/j. joca.2010.05.003.

Schmitt J (2014): Expertise zum Bedarf an Leistungserbringern für die Versorgung von orthopädischen und unfallchirurgischen Erkrankungen in Deutschland bis 2050. Berlin: Deutsche Gesellschaft für Orthopädie und Unfallchirurgie e. V. [German orthopedics and trauma surgery association].

Statistisches Bundesamt [Federal Statistical Office] (2013): Gesundheit. Grunddaten der Vorsorge- oder Rehabilitationseinrichtungen. Fachserie 12 Reihe 6.1.2.

Statistisches Bundesamt [Federal Statistical Office] (2014): Gesundheit. Fallpauschalenbezogene Krankenhausstatistik (DRG-Statistik) Operationen und Prozeduren der vollstationären Patientinnen und Patienten in Krankenhäusern - Ausführliche Darstellung - 2013. Wiesbaden.

Stöckle U, Lucke M \& Haas NP (2005): Der Oberschenkelhalsbruch. Deutsches Ärzteblatt 102(49), A3424-3434.

Strohm PC, Raschke M, Hoffmann R \& Josten C (2015): Frakturhüftendoprothetik in der deutschen Unfallchirurgie: Eine Standortbestimmung. 118(2), 173-176. DOI: 10.1007/s0011301427211.

Sun Y, Stürmer T, Günther KP, Brenner H (1997): Inzidenz und Prävalenz der Cox- und Gonarthrose in der Allgemeinbevölkerung. Z Orthop 135, 184-192.

Wilken F, Banke IJ, Laux F, Hauschild M, Von Eisenhart-Rothe R \& Gradinger R (2014): So wird der Hüftgelenkersatz geplant. MMW - Fortschritte der Medizin 156(17), 50-54.

Wirtz DC (2011): AE-Manual der Endoprothetik - Knie. Heidelberg: Springer. ISBN: 978-3-642-12888-2. 